\title{
Differences in Emotional Distress Among Black and White Breast Cancer Survivors During the Covid-19 Pandemic: a National Survey
}

\author{
Tamara Hamlish $^{1}$ (D) Elizabeth Lerner Papautsky ${ }^{2}$ (D)
}

Received: 29 November 2020 / Revised: 2 February 2021 / Accepted: 4 February 2021 / Published online: 23 February 2021

(C) W. Montague Cobb-NMA Health Institute 2021

\begin{abstract}
The Covid-19 pandemic is straining US healthcare resources, causing significant disruptions in cancer care. Prior to the pandemic, Black cancer survivors experienced a disproportionate burden of delays in cancer treatment compared to White cancer survivors. As a result of the pandemic, disruptions in care are widespread and affect cancer survivors regardless of race. This shift presented an opportunity to investigate differences in how Black and White cancer survivors experience disruptions in cancer care due to the pandemic. We conducted a national survey of adult breast cancer survivors, distributed online from 4/2/20 to 4/27/ 20. We used $t$-tests to compare cancer and non-cancer-related worry during the Covid-19 pandemic between Black and White breast cancer survivors. Analysis of data from 570 respondents (106 Black and 464 White) indicated significantly higher levels of distress among White respondents compared to Black respondents. Our results point to the importance of assessing race differences in emotional response to disruptions in cancer care during the pandemic. We suggest that differences in emotional distress may reflect differences in previous experience of treatment delays and coping strategies between Black and White breast cancer survivors.
\end{abstract}

Keywords Covid-19 · Breast cancer $\cdot$ Health disparities $\cdot$ Emotional distress

\section{Background}

The 2019 novel coronavirus disease (Covid-19) pandemic has strained healthcare resources in the USA, resulting in serious disruptions in care for those with chronic diseases. A study from the American Cancer Society showed that during the early days of the pandemic, 1 in 4 cancer survivors experienced delays in cancer care [1]. In our survey of breast cancer patients and survivors, more than $40 \%$ of respondents reported that their treatment was postponed or canceled [2]. Models estimating excess deaths due to the pandemic suggest that cancer mortality will rise over the next decade as a

Tamara Hamlish

hamlish@uic.edu

1 University of Illinois Cancer Center, 818 S. Wolcott, Chicago, IL 60612, USA

2 Department of Biomedical \& Health Information Science, University of Illinois at Chicago, 1919 W. Taylor St., Chicago, IL 60612, USA consequence of interruptions in cancer screening, diagnosis, and treatment $[3,4]$. Concerns over disruptions in cancer care, and estimates of excess cancer mortality, come from the knowledge that delays in care are associated with reduced overall survival, putting cancer survivors at risk for increased morbidity and mortality.

For Black cancer survivors, however, delays in cancer care are not limited to the pandemic. Treatment delays due to the pandemic are layered upon well-documented delays in timeto-treatment across the whole of the cancer care continuum [5-8]. Black breast cancer survivors experience longer intervals compared to White breast cancer survivors from first symptom to diagnosis and for all types of treatment. Racial inequities are found in time to diagnosis, surgery $[9,10]$, and adjuvant chemotherapy $[11,12]$. Racial inequities have also been found in treatment duration; results from the Carolina Breast Cancer Study indicate that Black women experienced 1.73 times higher odds of significant delays in treatment initiation and 1.69 odds of longer treatment duration compared to White women[13]. Racial inequities in time to treatment have been linked to racial disparities in mortality [14-16]. A number of factors have been identified as contributing to delays in 
care for Black breast cancer survivors, many of which are related more broadly to healthcare system barriers that limit access to care [17-19].

Prior to the pandemic, treatment delays were part of systemic and structural health inequities in the USA. The impact of these inequities had the greatest impact on Black breast cancer survivors, with significant disparities in mortality compared to White breast cancer survivors. Limited access to cancer care during the pandemic has provided a window into the risks and consequences of delays in cancer care for cancer health outcomes $[3,11]$. We know of no studies, however, that explore how patients experience delays and, in particular, their emotional response to interruptions in care that may extend time-to-treatment. The current study examines survivors' concerns about disruptions in cancer care and explores emotional distress among Black and White cancer survivors during the Covid-19 pandemic.

\section{Methods}

Data for these analyses come from a larger data set collected through a 50-item survey instrument administered to breast cancer survivors in the USA to assess the impact of Covid-19 on breast cancer care. The survey was reviewed and piloted by two breast cancer survivors and one clinician. We employed the National Cancer Institute definition of cancer survivor, which defines a person as a cancer survivor from the time of diagnosis until the end of life. The survey was administered electronically using Research Electronic Data Capture (REDCap) hosted at the University of Illinois at Chicago. We used snowball sampling to recruit adult ( $>18$ years old) breast cancer survivors in the USA. Survey invitations were distributed via social media and email to breast cancer survivor support networks. The demographics of respondents are detailed in an earlier publication [2]

All items included in the current analyses were developed specifically for this study. All worry items were on a scale of 0 (disagree)-100 (agree). Three items were designed to elicit responses regarding worry about cancer care. Two items were designed to elicit responses regarding worry about other health issues. Individual items and aggregates are identified in Table 1.

All analyses used SPSS version 26 statistical software and Excel. Descriptive statistics of counts, proportions, means, and standard deviations were calculated. Inferential statistics used were $t$-tests. The study was

Table 1 Descriptive statistics and $t$-tests associated with Race

\begin{tabular}{|c|c|c|c|c|c|c|c|c|c|c|c|c|}
\hline & \multirow[t]{2}{*}{ Race } & \multirow[t]{2}{*}{$N$} & \multirow[t]{2}{*}{ Mean } & \multirow[t]{2}{*}{$S D$} & \multirow[t]{2}{*}{$S E$} & \multirow[t]{2}{*}{$t$} & \multirow[t]{2}{*}{$d f$} & \multirow{2}{*}{\multicolumn{2}{|c|}{ Sig. (2-tailed) }} & \multicolumn{2}{|c|}{$\begin{array}{l}\text { 95\% Confidence } \\
\text { Interval of the Diff }\end{array}$} & \multirow[t]{2}{*}{ Missing } \\
\hline & & & & & & & & & & Lower & Upper & \\
\hline \multicolumn{13}{|l|}{ Means } \\
\hline \multirow[t]{2}{*}{ All-health-related worry (mean) } & Black & 65 & 48.03 & 24.39 & 3.03 & -3.46 & 421 & 0.001 & $* *$ & -16.10 & -4.44 & 147 \\
\hline & White & 358 & 58.30 & 21.54 & 1.14 & & & & & & & \\
\hline \multirow[t]{2}{*}{ Cancer-related worry (mean) } & Black & 74 & 34.79 & 29.21 & 3.40 & -3.28 & 445 & 0.001 & $* *$ & -19.47 & -4.89 & 123 \\
\hline & White & 373 & 46.97 & 29.13 & 1.51 & & & & & & & \\
\hline \multirow[t]{2}{*}{ Non-cancer-related worry (mean) } & Black & 80 & 68.30 & 28.84 & 3.22 & -2.96 & 495 & 0.003 & $* *$ & -13.91 & -2.80 & 73 \\
\hline & White & 417 & 76.66 & 21.92 & 1.07 & & & & & & & \\
\hline \multicolumn{13}{|l|}{ Individual Items } \\
\hline \multirow{2}{*}{$\begin{array}{l}\text { I am worried about delays/interruptions to my } \\
\text { cancer care because of COVID- } 19 \text {. }\end{array}$} & Black & 87 & 45.52 & 37.03 & 3.97 & -3.65 & 523 & 0.000 & $* *$ & -22.52 & -6.75 & 45 \\
\hline & White & 438 & 60.16 & 33.60 & 1.61 & & & & & & & \\
\hline \multirow{2}{*}{$\begin{array}{l}\text { I am worried my treatment will take longer than } \\
\text { I anticipated because of COVID- } 19 \text {. }\end{array}$} & Black & 80 & 34.78 & 34.85 & 3.90 & -1.47 & 471 & 0.140 & & -15.46 & 2.23 & 97 \\
\hline & White & 393 & 41.39 & 37.04 & 1.87 & & & & & & & \\
\hline \multirow{2}{*}{$\begin{array}{l}\text { I am worried my cancer will get worse or spread } \\
\text { during the COVID-19 pandemic. }\end{array}$} & Black & 83 & 26.82 & 30.61 & 3.36 & -4.28 & 493 & 0.000 & $* *$ & -25.61 & -9.48 & 75 \\
\hline & White & 412 & 44.36 & 34.76 & 1.71 & & & & & & & \\
\hline \multirow{2}{*}{$\begin{array}{l}\text { I am worried about my general health during } \\
\text { the COVID-19 pandemic. }\end{array}$} & Black & 86 & 65.81 & 35.35 & 3.81 & -2.62 & 511 & 0.010 & $*$ & -15.29 & -2.19 & 57 \\
\hline & White & 427 & 74.56 & 26.57 & 1.29 & & & & & & & \\
\hline \multirow[t]{2}{*}{ I am worried about getting COVID-19. } & Black & 86 & 70.40 & 29.92 & 3.23 & -2.68 & 517 & 0.010 & $*$ & -13.50 & -2.07 & 51 \\
\hline & White & 433 & 78.18 & 23.45 & 1.13 & & & & & & & \\
\hline
\end{tabular}


reviewed by the University of Illinois at Chicago's Institutional Review Board (Protocol \#2020-0371; Exemption Granted: 3/27/20).

\section{Results}

From 4/2/20 to 4/27/20, 633 respondents ( 1 male) completed the survey. We examined the differences between Black and White respondents only, yielding a sample size of 570 respondents $(81 \%$ were White and $19 \%$ were Black), with an average age of 47.92 ( $\mathrm{SD}=10.86$ ) (White: $\mathrm{M}=47.18, \mathrm{SD}=10.97$; Black: $\mathrm{M}=51.16, \mathrm{SD}=9.78)$. The average age at diagnosis was $42.59(\mathrm{SD}=10.17)$. The top three states of residence were Illinois (15\%), California (9\%), and Texas (8\%). More than half of respondents are currently receiving cancer treatment (63\%) and have employer-sponsored health insurance (67\%). Respondents receive cancer care at academic medical centers (45\%), physician's offices (26\%), or community hospitals $(21 \%)$. Approximately $60 \%$ reported being currently in treatment and $42 \%$ reported experiencing delays in care due to the pandemic.

Using $t$-tests, we compared levels of worry for White and Black respondents. White respondents reported significantly greater levels of worry compared to Black respondents. This includes worry regarding both cancer-related $(\mathrm{M}=46.97, \mathrm{SD}$ $=29.13$ and $\mathrm{M}=34.79, \mathrm{SD}=29.21$, respectively) $t(445)=$ $-3.28, p<.001$ and non-cancer-related health $(\mathrm{M}=76.66, \mathrm{SD}$ $=21.92$ and $\mathrm{M}=68.30, \mathrm{SD}=28.84$, respectively) $t(495)=$ $-3.65, p<.003)$. This is also the case for all health-related worry $(\mathrm{M}=58.30, \mathrm{SD}=21.54$ and $\mathrm{M}=48.03, \mathrm{SD}=24.39$, respectively) $t(421)=-3.46, p<.001$. In Table 1 , we represent means, standard deviations, and $t$-test results for individual items and aggregated worry scores.

\section{Discussion}

Our results indicate that White breast cancer survivors experienced significantly higher levels of emotional distress with respect to the impact of the pandemic on their cancer care, overall health, and risk of coronavirus infection compared to Black breast cancer survivors.

There are a number of challenges in drawing comparisons of our study results with the existing literature, not only because of the unprecedented and pervasive impact of the Covid-19 pandemic on the US healthcare system and the larger society but also because there is limited research on emotional distress in response to the challenges of navigating the US healthcare system. The National Comprehensive Cancer Network Guidelines for Distress Management set an expectation that all cancer survivors will experience some level of distress, defined as a multifactorial, unpleasant experience of a psychologic (i.e., cognitive, behavioral, emotional), social, spiritual, and/or physical nature that may interfere with the ability to cope effectively with cancer, its physical symptoms, and its treatment [20]. Screening tools such as the NCCN Distress Thermometer are frequently used to capture the level of distress (anxiety, depression, fear) related to a broad range of problems or issues. These screening tools do not, however, capture emotional distress related to disruptions in cancer care, uncertainties in time to treatment, or treatment delays.

Emerging studies on cancer care delays during the pandemic have focused on the rate and type of delays [1,2], clinical responses and potential consequences [21-23], and risk of Covid-19 infection or mortality among cancer survivors [24-27]. Studies on psychological distress during the pandemic indicate that both women and those with existing health conditions are at greater risk for distress, but have not indicated racial differences or disparities [28, 29]. Research on racial disparities in Covid-19 have focused on incidence and mortality resulting from social determinants and deeply rooted structural inequities; however, none of these studies has systematically explored psychosocial responses to these circumstances.

Our study results indicating racial differences in emotional distress related to delays or disruptions in cancer care during the pandemic may reflect respondents' previous experience with access to care and time to treatment. White breast cancer survivors may be experiencing barriers to care and delays in treatment that they do not typically experience, resulting in higher emotional distress. In comparison, Black breast cancer survivors may have previous experiences with delays in treatment and use existing coping strategies to manage emotional distress.

Racial difference in breast cancer coping strategies outlined by Reynolds [30] may provide insights into racial differences in emotional distress during the pandemic. She notes that Black survivors were more likely to rely on suppressing emotions, wishful thinking, and positive reappraisal. In contrast, White survivors were more likely to rely on expressing emotions, problem-solving, and escapism. While Reynolds does not address the broader context in which these strategies emerged, strategies employed by Black survivors may be more effective than the strategies used by White survivors for managing distress related to delays in care.

Differences in levels of emotional distress between Black and White breast cancer survivors may also reflect the broader impact of the pandemic itself. Black communities in the USA have experienced higher rates of Covid-19 infection and mortality and higher risk of changes in employment and income, health insurance, household composition, and other social determinants of health. Under these circumstances, Black breast cancer survivors may be struggling to balance multiple competing and urgent priorities, making their own health, including delays in cancer care, a lower priority $[25,31]$. 


\section{Conclusion}

The 2019 novel coronavirus disease (Covid-19) pandemic has laid bare deep-seated and longstanding health inequities in the USA. Much of this discussion has focused on disparities in Covid-19 incidence and mortality, pointing to profound structural inequities in disease risk, access to high-quality medical care, and social determinants such as access to health insurance, reliable childcare, and paid sick leave. Our results point to the importance of bringing patient experiences into this discussion. Our data indicate differences in Black and White breast cancer survivors' emotional response to disruptions in cancer care due to the Covid-19 pandemic. We have suggested possible explanations, including differences in previous experiences with the healthcare system or coping strategies. However, these questions merit further research, not only to gain a systematic understanding of emotional distress related to barriers to healthcare access but also to determine how differences in emotional distress contribute to disparities in cancer health outcomes.

\section{Limitations}

Our study has several limitations. Due to the unprecedented circumstances of a global pandemic, no validated questionnaire on this topic existed. As noted above, previous studies of emotional distress do not measure distress in response to difficulties navigating the healthcare system. Given the urgency of collecting real-time data, we were not able to validate this survey before distributing. Recruitment through social media may not be representative of all breast cancer patients and may result in a selection bias with a higher response rate by younger survivors.

\footnotetext{
Acknowledgements We are grateful to numerous colleagues, patient advocates, community members, and friends who helped to distribute the survey (Dr. Deanna Attai, Mrs. Beulah Brent, Miss Sophia Williams, Ms. Dikla Benzeevi, Ms. Ricki Fairley, Dr. Sasha Milicevic, Ms. Sarah Rittner, Ms. Christine Jonel, Sisters Working It Out, Metavivor Research and Support, Recovery on Water, Chicago Breasties, and the Breast Cancer Resource Center). Dr. Zhengjia Chen provided statistical support. The UIC Center for Clinical and Translational Science UL1TR002003 provided access to REDCap and associated technical support.
}

Availability of Data and Material The datasets generated during and/or analyzed during the current study are available from the corresponding author on reasonable request.

\section{Declarations}

Conflict of Interest The authors declare no competing interests.

\section{References}

1. American Cancer Society Cancer Action Network, "COVID-19 pandemic impact on cancer patients and survivors survey findings summary," 2020. Accessed: Oct. 24, 2020. [Online]. Available: https://www.fightcancer.org/policy-resources/covid-19-pandemicearly-effects-cancer-patients-and-survivors-april-2020.

2. Papautsky EL, Hamlish T. Patient-reported treatment delays in breast cancer care during the COVID-19 pandemic. Breast Cancer Res Treat. 2020;184(1):249-54. https://doi.org/10.1007/s10549020-05828-7.

3. Sharpless NE. COVID-19 and cancer. Science. 2020;368(6497) American Association for the Advancement of Science:1290. https://doi.org/10.1126/science.abd3377.

4. Sud A, Torr B, Jones ME, Broggio J, Scott S, Loveday C, et al. Effect of delays in the 2-week-wait cancer referral pathway during the COVID-19 pandemic on cancer survival in the UK: a modelling study. Lancet Oncol. 2020;21(8):1035-44. https://doi.org/10.1016/ S1470-2045(20)30392-2.

5. Gorin SS, Heck JE, Cheng B, Smith SJ. Delays in breast cancer diagnosis and treatment by racial/ethnic group. Arch Intern Med. 2006;166(20):2244-52. https://doi.org/10.1001/archinte.166.20. 2244.

6. Halpern MT, Holden DJ. Disparities in timeliness of care for U.S. Medicare patients diagnosed with cancer. Curr Oncol. 2012;19(6): e404. https://doi.org/10.3747/co.19.1073.

7. Hoppe EJ, Hussain LR, Grannan KJ, Dunki-Jacobs EM, Lee DY, Wexelman BA. Racial disparities in breast cancer persist despite early detection: analysis of treatment of stage 1 breast cancer and effect of insurance status on disparities. Breast Cancer Res Treat. 2019;173(3):597-602. https://doi.org/10.1007/s10549-018-5036-z.

8. Obeng-Gyasi S, Oppong B, Paskett ED, Lustberg M. Purposeful surgical delay and the coronavirus pandemic: how will black breast cancer patients fare? Breast Cancer Res Treat. 2020;182(3) Springer:527-30. https://doi.org/10.1007/s10549-020-05740-0.

9. Bekeny JC, Luvisa K, Wirth P, Singh T, Black CK, Greenwalt I, et al. Critical evaluation of factors contributing to time to mastectomy within a single health care system. Breast J. 2020;26(9):170211. https://doi.org/10.1111/tbj.13953.

10. Sheppard VB, Oppong BA, Hampton R, Snead F, Horton S, Hirpa $\mathrm{F}$, et al. Disparities in breast cancer surgery delay: the lingering effect of race. Ann Surg Oncol. 2015;22(9):2902-11. https://doi. org/10.1245/s10434-015-4397-3.

11. Balasubramanian BA, Demissie K, Crabtree BF, Strickland PAO, Pawlish K, Rhoads GG. Black Medicaid beneficiaries experience breast cancer treatment delays more frequently than Whites. Ethn Dis. 2012;22(3):288-94 [Online]. Available: https://ethndis.org/ edonline/index.php/ethndis/article/view/452.

12. Fedewa SA, Ward EM, Stewart AK, Edge SB. Delays in adjuvant chemotherapy treatment among patients with breast cancer are more likely in African American and Hispanic populations: a national cohort study 2004-2006. J Clin Oncol. 2010;28(27):413541. https://doi.org/10.1200/JCO.2009.27.2427.

13. Emerson MA, et al. Breast cancer treatment delays by socioeconomic and health care access latent classes in Black and White women. Cancer. 2020:cncr.33121. https://doi.org/10.1002/cncr. 33121.

14. Bleicher RJ, Ruth K, Sigurdson ER, Beck JR, Ross E, Wong YN, et al. Time to surgery and breast cancer survival in the United States. JAMA Oncol. 2016;2(3):330-9. https://doi.org/10.1001/ jamaoncol.2015.4508.

15. A. A. Khorana et al., "Time to initial cancer treatment in the United States and association with survival over time: an observational study," PLoS One, vol. 14, no. 3, 2019, doi: https://doi.org/10. 1371/journal.pone.0213209. 
16. Smith EC, Ziogas A, Anton-Culver H. Delay in surgical treatment and survival after breast cancer diagnosis in young women by race/ethnicity. JAMA Surg. 2013;148(6):516-23. https://doi.org/ 10.1001/jamasurg.2013.1680.

17. Farias AJ, Ochoa CY, Toledo G, Bang SI, Hamilton AS, Du XL. Racial/ethnic differences in patient experiences with health care in association with earlier stage at breast cancer diagnosis: findings from the SEER-CAHPS data. Cancer Causes Control. 2020;31(1): 13-23. https://doi.org/10.1007/s10552-019-01254-3.

18. Molina Y, Silva A, Rauscher GH. Racial/ethnic disparities in time to a breast cancer diagnosis: the mediating effects of health care facility factors. Med Care. 2015;53(10):872-8. https://doi.org/10. 1097/MLR.0000000000000417.

19. Warnecke RB, Campbell RT, Vijayasiri G, Barrett RE, Rauscher GH. Multilevel examination of health disparity: the role of policy implementation in neighborhood context, in patient resources, and in healthcare facilities on later stage of breast cancer diagnosis. Cancer Epidemiol Biomark Prev. 2019;28(1):59-66. https://doi. org/10.1158/1055-9965.EPI-17-0945.

20. Riba MB, et al. Distress management, version 3.2019. JNCCN J Nat Compreh Cancer Netw. 2019;17(10) Harborside Press:122949. https://doi.org/10.6004/jnccn.2019.0048.

21. Boffa DJ, et al. Results of COVID-minimal surgical pathway during surge-phase of COVID-19 pandemic. Ann Surg. 2020. https:// doi.org/10.1097/SLA.0000000000004455.

22. Butler J, et al. New approaches to cancer care in a COVID-19 world. Lancet Oncol. 2020;21(7) Lancet Publishing Group:e33940. https://doi.org/10.1016/S1470-2045(20)30340-5.

23. The Lancet Oncology. Safeguarding cancer care in a post-COVID19 world. Lancet Oncol. 2020;21(5):603. https://doi.org/10.1016/ S1470-2045(20)30243-6.

24. de las Heras B, et al. Cancer treatment and research during the COVID-19 pandemic: experience of the first 6 months. Oncol Ther. 2020:1-12. https://doi.org/10.1007/s40487-020-00124-2.
25. Kuderer NM, Choueiri TK, Shah DP, Shyr Y, Rubinstein SM, Rivera DR, et al. Clinical impact of COVID-19 on patients with cancer (CCC19): a cohort study. Lancet. 2020;395(10241):190718. https://doi.org/10.1016/S0140-6736(20)31187-9.

26. Park R, Chidharla A, Mehta K, Sun W, Wulff-Burchfield E, Kasi A. Sex-bias in COVID-19-associated illness severity and mortality in cancer patients: a systematic review and meta-analysis. EClinicalMedicine. 2020;26. https://doi.org/10.1016/j.eclinm. 2020.100519 .

27. Zhang H, Wang L, Chen Y, Wu Q, Chen G, Shen X, et al. Outcomes of novel coronavirus disease 2019 (COVID-19) infection in 107 patients with cancer from Wuhan, China. Cancer. 2020;126(17):4023-31. https://doi.org/10.1002/cncr.33042.

28. Pfefferbaum B, North CS. Mental health and the Covid-19 pandemic. N Engl J Med. 2020;383(6):510-2. https://doi.org/10.1056/ NEJMp2008017.

29. Xiong J, et al. Impact of COVID-19 pandemic on mental health in the general population: a systematic review. J Affect Disord. 2020;277. Elsevier B.V.:55-64. https://doi.org/10.1016/j.jad.2020. 08.001.

30. Reynolds P, Hurley S, Torres M, Jackson J, Boyd P, Chen VW. Use of coping strategies and breast cancer survival: results from the Black/White Cancer Survival Study. Am J Epidemiol. 2000;152(10). https://doi.org/10.1093/AJE/152.10.940.

31. Watson NN, Hunter CD. Anxiety and depression among African American women: the costs of strength and negative attitudes toward psychological help-seeking. Cult Divers Ethn Minor Psychol. 2015;21(4):604-12. https://doi.org/10.1037/cdp0000015.

Publisher's Note Springer Nature remains neutral with regard to jurisdictional claims in published maps and institutional affiliations. 